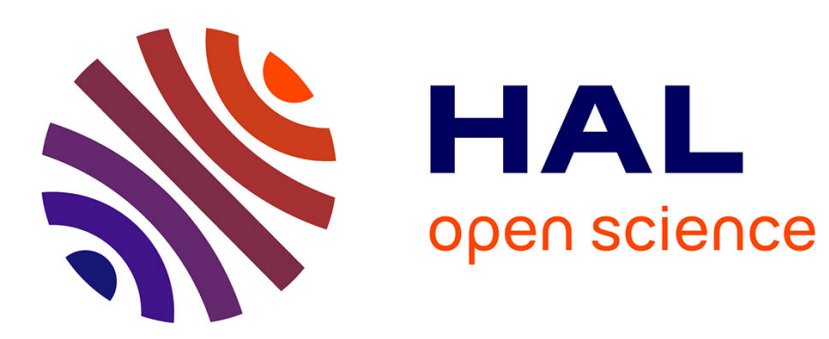

\title{
Cognitive Dysfunction in Obsessive-Compulsive Disorder
}

Nabil Benzina, Luc Mallet, Eric Burguière, Karim N'diaye, Antoine Pelissolo

\section{To cite this version:}

Nabil Benzina, Luc Mallet, Eric Burguière, Karim N'diaye, Antoine Pelissolo. Cognitive Dysfunction in Obsessive-Compulsive Disorder. Current Psychiatry Reports, 2016, 18 (9), pp.80. 10.1007/s11920016-0720-3 . hal-01440786

\section{HAL Id: hal-01440786 \\ https://hal.sorbonne-universite.fr/hal-01440786}

Submitted on 19 Jan 2017

HAL is a multi-disciplinary open access archive for the deposit and dissemination of scientific research documents, whether they are published or not. The documents may come from teaching and research institutions in France or abroad, or from public or private research centers.
L'archive ouverte pluridisciplinaire HAL, est destinée au dépôt et à la diffusion de documents scientifiques de niveau recherche, publiés ou non, émanant des établissements d'enseignement et de recherche français ou étrangers, des laboratoires publics ou privés. 


\title{
Cognitive dysfunction in obsessive-compulsive disorder
}

\author{
Nabil Benzina (1), Luc Mallet (1,2), Eric Burguière (1), Karim N’Diaye (1),
} Antoine Pelissolo (2)

1. Behaviour, Emotion, and Basal Ganglia, Inserm U 1127, CNRS UMR 7225, Sorbonne Universités, UPMC Univ Paris 06 UMR S 1127, Institut du Cerveau et de la Moelle épinière, ICM, F-75013, Paris, France.

2. AP-HP, service de psychiatrie et DHU PePSy, Hôpital Henri-Mondor, Université Paris-Est Créteil, INSERM U955, Fondation FondaMental, Créteil, France.

N. BENZINA (corresponding author)

Team "Behavior, Emotion, and Basal Ganglia"

Institut du Cerveau et de la Moelle épinière

Groupe Hospitalier Pitié-Salpêtrière

47-83, boulevard de l'Hôpital

75013 Paris

France

Phone: +33157274514

E-mail: $\underline{\text { nabil.benzina@inserm.fr }}$ 


\section{Abstract}

Obsessive-Compulsive Disorder (OCD) is a mental disorder featuring obsessions (intrusive thoughts) and compulsions (repetitive behaviors performed in the context of rigid rituals). There is strong evidence for a neurobiological basis of this disorder, involving limbic cortical regions and related basal ganglia areas. However, more research is needed to lift the veil on the precise nature of that involvement and the way it drives the clinical expression of OCD. Altered cognitive functions may underlie the symptoms and thus draw a link between the clinical expression of the disorder and its neurobiological etiology. Our extensive review demonstrates that OCD patients do present a broad range of neuropsychological dysfunctions across all cognitive domains (memory, attention, flexibility, inhibition, verbal fluency, planning, decision-making) but some methodological issues temper this observation. Thus, future research should have a more integrative approach to cognitive functioning, gathering contributions of both experimental psychology and more fundamental neurosciences.

\section{Keywords}

Attention; Obsessive-compulsive disorder; Cognitive dysfunction; Memory; Neuropsychology. 


\section{Introduction}

Obsessive-compulsive disorder (OCD) affects $2-3 \%$ of the general population, and is one of the most disabling psychiatric disorders. It is characterized by recurrent, intrusive and unwanted thoughts, impulses and images, often associated with compulsive behaviors that are repetitive, time consuming and often ritualized. The most common obsessions involve contamination, doubting, ordering or symmetry, aggressive thoughts, sexual imagery and religion. Compulsions are generally performed in an attempt to either avoid or neutralize the obsessions, or more specifically, the anxiety associated with them. Common compulsions include washing or cleaning, checking, ordering, counting and repeating actions or words. Considering the core clustering of OCD symptoms and the recent findings of the neuronal basis of this pathology, OCD has newly been separated from the class of anxiety disorders in the $5^{\text {th }}$ edition of the Diagnostic and Statistical Manual of Mental Disorders [1].

Current approaches to obsessive-compulsive disorder suggest that neurobiological abnormalities play a crucial role in the etiology and course of OCD. Both structural and functional imaging in OCD point towards hyperactivity in limbic and associative cortical regions (anterior cingulate cortex (ACC) and orbitofrontal cortex (OFC)) and related basal ganglia areas [2]. Additionally, some studies identified abnormalities in cortico-basal ganglia circuits in OCD [3]. Indeed, in $\mathrm{FMRI}$ and PET studies in OCD patients, abnormal hemodynamic responses in the OFC and ACC may decrease as patients improve either through deep brain stimulation [4], psychotherapy [5] or medications [6]. These data support the involvement of limbic frontal-basal ganglia loops in OCD, and suggest that their dysfunctions might result in pathological doubt, obsessive anxiety and compulsive behaviors. However, the nature of the deficits and their involvement in the pathophysiology of OCD remain unclear.

To address these questions, there is a need to better characterize and assess the neuropsychological deficits that underlie the symptoms. Indeed, neuropsychological functioning has been proposed as an intermediate phenotype that lies somewhere between the clinical manifestation of the disorder and its neurobiological etiology. Another interest of this approach is its potential impact on treatments, for example through cognitive remediation.

Numerous studies have investigated cognitive deficits of patients suffering from OCD, bringing inconsistent results with differential performances on identical or similar tasks, often due to methodological discrepancies. Some studies have even used self-report questionnaires to assess cognitive functioning with an obvious high risk of unreliability. The aim of this review is therefore to provide a more global and comprehensive description of cognitive performance in OCD patients, supported by recent studies and focusing on seven main cognitive fields: memory, attention, flexibility, inhibition, verbal fluency, planning and decision-making. 


\section{Memory}

Most patients with OCD report that they are uncertain whether they have carried out an action correctly as opposed to merely imagining that they have done so. Apparently as a result of these uncertainties, they frequently engage in repetitive rituals, such as compulsive checking of their gas stove. On the basis of these clinical observations, some studies have been carried out in order to examine possible memory deficits in OCD patients.

It is important to note that memory is not a unitary phenomenon, but instead involves a number of somewhat independent processes [7]. Most of the studies have focused on episodic memory, the one that appears most relevant to OCD. Episodic memory refers to memory for personal events dated in one's past. Nonetheless, many different subtypes of episodic memory have been described, including memory for verbal and non-verbal forms of information.

Recent investigations conducted during the past decade have produced inconsistent results on whether or not OCD patients present poorer performance than controls on verbal memory tasks. Indeed, depending on the task used to explore verbal memory, patients perform poorer or as well as healthy controls. For example, in the California Verbal Learning Test (CVLT) and its derivatives, OCD patients present a deficit [8-11]. The same result is found when using the subtests Logical Memory I and II from the Wechsler Memory Scale-Revised (LM-WMS-R)[12-14]. Concerning the Rey Auditory Verbal Learning Test (RAVLT), the results are more mixed with some studies finding a deficit [15-17], while others do not [18-20]. Finally, there are some tasks where patients do not present any deficit like the Digit Span (DS) [19,21-24], the Selective Reminding Test (SRT) [21], and the item 223 of the Luria-Nebraska neuropsychological battery (LNNB) [25].

So, how can these discrepancies among results be explained? Leaving aside the methodological factors which certainly play a role (small samples, heterogeneity in exclusion criteria, etc.), the explanation could arise from the tasks used themselves. Indeed, while the CVLT, the LMWMS-R and the RAVLT are widely validated for episodic verbal memory assessment, the others are not, in particular the DS, a task which tap on attentional abilities of the subject too. Another explanation could be found in the involvement of organizational strategies (the strategy used to encode information). As many authors suggest, when an impairment is found, it is due to failures in the deployment of such strategies required by the tasks [26]. This idea is supported by Deckersbach et al. [27] who demonstrated that verbal memory impairment exhibited by OCD patients are associated with difficulties in spontaneously initiating verbal organization strategies during memory encoding. However, this ability to implement verbal organization is preserved when patients are instructed to do so. Moreover, it was demonstrated that OCD patients are slower to analyze the 
semantic features of the words in comparison to controls, although their accuracy in doing so was preserved. Thus this slowness in feature detection could be responsible for the encoding deficits too [28].

Concerning the nonverbal memory, the deficits reported are more consistent. The ReyOsterrieth Complex Figure Test (RCFT) is the most frequently employed task to assess nonverbal memory. It allows for assessment of both immediate and delayed recall, as well as evaluation of organizational strategies employed during the encoding (copying) phase. Regarding the two recall phases, OCD patients present impaired performance compared to healthy subjects $[10,15,16,18,19,21,25,29-34]$. In the encoding phase, the impairment is less clear with some studies finding no impairments $[10,17,19,25,30,32-34]$ while others do $[15,16,18,21,29,35]$. If the patients actually present an impairment in this phase, the deficit found in the recall phase could not could not be attributed to a memory impairment, but rather to reduced organizational strategies. Interestingly, almost all the studies that addressed this question are in line with impaired organizational strategies in OCD $[18,29,30,32,33]$. Mataix-Cols et al. [32] and Penadés et al. [33] went further by analyzing organizational strategies as a confounding factor of the nonverbal memory. Their results were in line with the hypothesis that impaired nonverbal memory have less to do with memory per se and more to do with flawed encoding strategies.

Another way to explore nonverbal memory relies on the Pattern Recognition paradigm. Although a few studies found an impairment in OCD patients using this paradigm [36,37], a majority does not $[28,38-41]$. This could be explained by the use of verbal mediation strategies which could mask a possible impairment as Olley et al. suggested [28].

Another component of nonverbal memory is spatial memory. Most of the studies assessing it found an impairment in OCD patients $[18,21,23,36,38-44]$. As Chamberlain et al. [26] suggest it, the commonly used tasks to explore this type of memory (the Spatial Working Memory task and the Spatial Recognition Task inter alia) are strategy dependent. Thus the impairment could be explained by strategy failures, as for the RCFT. This hypothesis is supported by the fact that in tasks requiring no encoding strategy like the Penn Facial Memory Test and comparable tasks, no deficit is found $[33,45]$.

In conclusion, whether for verbal or nonverbal episodic memory, OCD patients do present an impairment. This impairment is confirmed by the three meta-analysis performed by Shin et al. [46••], Abramovitch et al. [47••] and Snyder et al. [48••]. But there are strong arguments that tend to consider that this impairment is not due to a primary memory defect but rather to an alteration in encoding underpinned by a failure in organizational strategies.

\section{Attention}


Attention can be divided in four components: focused attention, the ability to concentrate on one sensory stimulus to the exclusion of all others; sustained attention, the ability to maintain a consistent behavioral response during continuous and repetitive activity; selective attention, the ability to maintain a behavioral or cognitive set in the face of distracting stimuli; divided attention, the ability to respond simultaneously to multiple tasks or multiple task demands.

Focused attention was the most studied across the literature. The Trail Making Task Part A (TMT-A), where the subject has to connect numbers sequentially, and its derivatives are frequently used by the studies exploring this type of attention in OCD patients. Although some studies did not find any defect $[8,13,17,19,25,49-51]$, the trend is towards a focused attention impairment in OCD patients $[11,14-16,18,20,24,30,33,34,52 \bullet]$. The meta-analyses performed by Shin et al. [46••] and Snyder et al. [48••], which had included 23 studies and 32 studies respectively evaluating this cognitive ability, confirmed this observation. We can also mention the study by Armstrong et al. [53], which, even though they used the Attentional Control Scale (ACS), a 20-item self-report questionnaire, led to the same conclusion.

Sustained attention is the second most studied type of attention. Although one of the reviewed studies did not find any impairment [19], there is strong evidence supporting an altered sustained attention in OCD patients with poorer performance on the Continuous Performance Test $[44-46 \bullet \bullet]$ and analogous tasks $[16,23,42]$.

There has been little research on selective attention, leading to mixed results. Indeed, two studies, one using the $\mathrm{d} 2$ test [54] and the other the ACS [53], found an impairment while another study using a different paradigm, a modified Choice Reaction Time task, did not [55]. Concerning the divided attention, although a very few studies addressed the question, the trend is towards an altered divided attention in OCD patients $[16,52 \bullet, 53]$.

In conclusion and considering the two meta-analysis performed by Shin et al. [46••] and Abramovitch et al. [47••], there is supporting evidence for altered attentional processes in patients suffering from $O C D$, regardless the type of attention. Even though more research is needed concerning the selective and divided attention to confirm the impairment. Some authors suggested with good reasons that these impairments could be explained by prescribed psychotropic drugs and/or psychiatric comorbidities. This hypothesis is weakened by the study of Rajender et al. [16] which included only drug-naïve patients without any psychiatric comorbidity and did find an impairment of attentional performances.

\section{Flexibility}


As already mentioned, OCD is characterized by repetitive behavior, performed through rigid rituals. This phenomenological observation has led to explore the idea that OCD patients have a diminished behavioral flexibility, which is ability to change one's behavior according to contextual cues.

Different tasks were designed to assess this cognitive dimension. The most classical are the Trail Making Task Part B (TMT-B) where the subject has to connect letters and numbers sequentially, alternating between them; and the Wisconsin Card Sorting Test (WCST) where the subject has to classify cards according to an implicit and changing rule. On the TMT-B, the results seem to be inconsistent with some studies finding equal performances between OCD patients and healthy controls $[13,19,20,25,34,35,51]$ while others do not $[11,17,30,33]$. With the WCST, there is far less inconsistencies, especially with regard to perseverative errors, with a pronounced trend towards poorer performance exhibited by OCD patients $[8,11,14-16,19,22,34-36,40,44,45,51,56-61]$; even though some studies failed to report this difference $[13,21,24,25,31,49,62,63]$. The three meta-

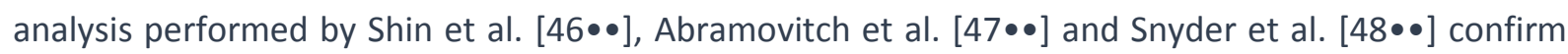
this trend for WCST but also for the TMT-B despite the apparent inconsistency.

More recently, computerized tasks were developed to assess behavioral flexibility with more specificity and in a more controlled fashion. Indeed, even though they were designed to assess flexibility, the TMT-B and WCST are not specific to this cognitive dimension; other processes are involved such as attention, speed processing, motor speed, or working memory. Moreover, the testtaking conditions (presence of an assessor for example) may affect the results and impact the reliability of these tasks. That is how three paradigms have recently come into use: the Reversal Learning (RL), the Intra/Extra-dimensional Set Shifting (ID/ED) and the Task Switching (TS). However, the studies using these paradigms in the context of OCD are still limited and leading to inconsistent findings. For example with the RL paradigm, two studies did find poorer performance in OCD patients $[64,65]$ but six did not $[38,59 \bullet, 66-69]$. This inconsistency in RL paradigm is explained by the lack of homogeneity between studies concerning the measure of interest (some focusing on the number of trials to reach reversal criterion for example while others taking in account the total number of errors before reversal occurs or the number of perseverative errors just after a reversal) or even the task design itself (some studies have a reversal occurring after a fixed number of trials while others have a reversal criterion which ensure the subject made an association before to reverse the contingencies). Concerning the ID/ED paradigm, the findings are more consistent with seven studies demonstrating a difference [37,42,62,62,69-72] while only one do not [41]. Shin et al. [46••], Abramovitch et al. [47••] and Snyder et al. [48••] confirmed this observation with their respective meta-analyses. Finally, with the TS paradigm, the results are more mixed, with Gu et al. [73] finding an impairment in OCD patients while Moritz et al. [74] and Remijnse et al. [75] not. 
Thus, despite the apparent discrepancy depending on the paradigm used, for the most part, the evidence supports the hypothesis of an impaired behavioral flexibility in OCD. Concerning the paradigms with mixed results, namely the RL and the TS, it is important to note that the studies finding no difference in terms of number of errors, did find a difference in terms of reaction time. Indeed, OCD patients present a longer reaction time in these tasks, but in a very specific context: just before changing their response strategy after a reversal/task switch $[66-68,74,75]$. Interestingly, Valerius et al. [68] found that this prolonged reaction time positively correlates with the severity of compulsions, demonstrating stronger reluctance to change the response strategy with increasing compulsion severity in $O C D$ and thus a less flexible behavior than healthy controls. Finally, an interesting study conducted by Zetsche et al. [76•] revealed that the emotional context is an important factor to take into account for future research. They have indeed demonstrated, using a probabilistic classification learning paradigm, that OCD patients have an impaired behavioral flexibility compared to healthy controls only in an OCD-specific context, but not in a neutral one. This result suggests that activated disorder-specific fears may impair the flexible adoption of efficient behaviors.

\section{Inhibition}

Due to the inability to suppress repetitive and unpleasant thoughts and actions, inhibitory control dysfunction has long been theorized to be a central feature of OCD [26]. Inhibitory control is not a unitary function and consists of motor (or behavioral) response inhibition and interference control (or cognitive inhibition) [77]. Behavioral inhibition involves the inhibition of pre-potent and automatic motor responses. Cognitive inhibition, on the other hand, refers to the cognitive control needed to prevent interference due to competition by irrelevant stimuli or irrelevant stimulus characteristics.

Cognitive inhibition is mainly assessed by the Stroop task. Across the literature, while a few studies failed to report a difference using this task $[13,20,24,39,50,78,79]$, the vast majority of studies did [11,15,16,19,22,33,51,56,80-83]. More important, the meta-analysis performed by Shin et al. [46••], which included 12 studies for this task, confirms the impairment of OCD patients. However, a few studies used different paradigms to assess cognitive inhibition, yielding mixed results. For example, Bohne et al. [84] tested the subjects with a Directed Forgetting task and found a defect in OCD patients compared to healthy subjects only with negative valence words; echoing the observation made by Zetsche et al. [76•] for the behavioral flexibility. By contrast, 7 studies used the Flanker task and failed to find an impairment, when they did not find better performance in OCD patients [85-91]. Morein-Zamir et al. [92], using the Thought Stop-Signal task, found an intact 
unintentional thought suppression in OCD patients. Similarly, Moritz et al. [83] used a Negative Priming paradigm to assess cognitive inhibition and failed to show a difference between OCD and healthy groups. Nevertheless, while interesting, these studies are not sufficient to counterbalance the trend towards an impaired cognitive inhibition in OCD.

Concerning the motor response inhibition, this ability can be differentiated into action restraint and action cancelation. The Go/No Go task (G/NG), where the subject has to inhibit his response when a "No go" cue appears, is considered to probe action restraint; whereas the Stopsignal task (SST), where the subject has to inhibit an already initiated response when a "Stop" cue appears, measures action cancelation [77]. The results with G/NG are mixed with some studies showing altered performances in OCD patients [37,56,80,82,93•], while others do not [94-101]. By contrast, there is no ambiguity with SST as all the reviewed studies demonstrate an altered performance in OCD patients $[42,69,82,92,102-106]$.

In conclusion, there is supporting evidence towards an altered inhibitory control in OCD. This observation is confirmed by the meta-analyses realized by Shin et al. [46••], Abramovitch et al. [47••] and Snyder et al. [48••]. This alteration is expressed both in the cognitive and behavioral components of inhibition. Concerning the behavioral component, the impairment is unambiguous for action cancelation, while we can not conclude for action restraint. Interestingly, three studies showed that the emotional context affects the inhibitory control with threat [107], punishment [93•] or simply words with negative valence [84] worsening/revealing the impairment, as observed for flexibility [76•].

\section{Verbal fluency}

Verbal fluency is an indicator of both verbal ability (more specifically lexical access ability) and executive control [108]. Its assessment relies on the Controlled Oral Word Association Test (COWA) and its derivatives, a simple task where the subject have to say as many words as possible from a category in a given time (usually 60 seconds). This category can be semantic, such as animals, or phonemic, such as words that begin with letter $P$.

The literature is inconsistent concerning this dimension, with some studies showing an impairment $[11,17,20,24,25,31,34,35,52 \cdot]$ while others do not $[8,13,15,18,19,21,30,37,50,56,62,63]$. However, Shin et al. [46••] have incorporated in their meta-analysis 37 studies probing verbal fluency, and shown that OCD patients do have an impaired verbal fluency. The meta-analysis by Snyder et al. [48••] included 40 studies and reports the same result but, more importantly, also shows that the slowdown characterizing OCD patients does not explain this impairment. 


\section{Planning}

Planning is the process of thinking about and organizing the activities required to achieve a desired goal. This cognitive ability is probed by problem solving tasks like the Tower of Hanoi (ToH) and its derivatives.

According to the literature, there is a trend towards impaired planning ability in OCD patients $[11,15,18,30,36,38,39,42,51,52 \bullet, 58,69,78,109]$, although some studies do not support this result $[13,16,19,20,37,40,41,56,72]$. This observation is reflected in the three meta-analyses by Shin et al. [46••], Abramovitch et al. [47••] and Snyder et al. [48••] which did find a planning impairment in OCD, thereby establishing a link with memory impairment which relies on a failure in organizational strategies as we have seen above. Interestingly, the studies which do not find a difference in performance (number of moves needed to achieve the task), did find one in terms of planning, performance and movement time which are increased $[13,16,40,41,72]$. Thus, it indicates an abnormal slowing reflecting planning difficulties, but they may not be sufficient to impact the overall performance. Some could suggest that this slowing may be explained by the general slowdown showed by these patients. The meta-analysis by Snyder et al. [48••] addressed this issue and does not support this hypothesis.

\section{Decision-making}

Decision-making is a cognitive process resulting in a course of action among several alternative possibilities. OCD is characterized by chronic doubting and an apparent inability to make decisions. According to this observation, it has been suggested that compulsive behaviors in OCD may be conceptualized as failures in decision-making [26]. However, a few studies addressed this question with most of them using gambling paradigms to evaluate decision-making skills.

Among the reviewed literature, three studies found altered decision-making with the lowa Gambling Task (IGT) $[15,58,59 \bullet]$, while only one did not [110]. With the Cambridge Gambling Task (CGT), there is an opposite trend with only one study finding an alteration of decision-making [78], while three studies do not $[37,69,71]$. The discrepancy between these two results could be explained by the different nature of these tasks. Indeed, according to a behavioral economics dichotomy, the IGT probes decision-making under ambiguity (the state of the world i.e. the reward probability is unknown to the subject) while the CGT probes decision-making under risk (the reward probabilities are known to the subject). Therefore, OCD patients seem to have an impaired decision-making only under ambiguity, while they performed well under risk. This observation was confirmed by Kim et al. 
[59•] which compared OCD patients to healthy volunteers in IGT and the Game of Dice Task (GDT) for the risk context.

Another aspect of decision-making relies on information sampling, i.e. the ability to gather a sufficient amount of information to take a valid decision. The Information Sampling Task (IST) gives a convenient way to probe this ability. Only two studies were found to address the question of altered information sampling in OCD using this task. The one by Bersani et al. [42] did report an impairment but only in fixed win condition (i.e. the gain stays the same regardless the amount of information retrieved); the impairment disappearing in decreasing win condition (i.e. the more the subject picks up information, the less he wins). The other by Chamberlain et al. [38] found that OCD patients did not adapt their information sampling behavior in accordance with the change in reinforcement contingencies (i.e. switch between fixed and decreasing win). An interesting study by Banca et al. [111•] went further in the information sampling probing. Indeed, they applied a drift diffusion model to a Random-Dot Motion Task and found that, compared to healthy subjects, OCD patients have higher decision thresholds but only under high uncertainty. Moreover, they present a slower evidence accumulation regardless the uncertainty level. Their last observation was that by emphasizing speed (i.e. the slower is the subject, the greater is the loss), OCD subjects normalized their behavior.

In conclusion, OCD patients do have impaired decision-making. This impairment is limited to ambiguous/uncertain contexts and is reversible, the OCD patients being able to normalize their behavior when the situation expressly requires it (inadequate behavior leading to negative outcomes).

\section{Discussion and conclusion}

Despite some inconsistencies across the literature, OCD patients do present impairments across the seven studied cognitive domains; i.e. memory, attention, flexibility, inhibition, verbal fluency, planning and decision-making.

The inconsistencies described may be explained by the extensive use of traditional tests. Designed originally to ascertain the presence or absence of brain dysfunction, or overall skill level, they may not be sensitive to the subtle impairments that characterize OCD. However, more obvious explanations could be found, the first being methodological issues. Among them, small sample size is the more evident. Indeed, almost all the reviewed studies included on average twenty subjects per group. This means that small to moderate impairments would be difficult to detect, and it is possible that the null results reported by some of the studies are related to a lack of statistical power (Type II error). 
Another concern that came to light while reviewing the literature was the major tendency to study OCD as a homogeneous condition, including only global measures of symptom severity (e.g., the Yale-Brown Obsessive Compulsive Scale). That is, whereas the thematic heterogeneity and dimensional structure of OCD is well established [112], the vast majority of studies have made no attempts to examine possible associations between cognitive performances and OCD subtypes, nor assess the types of obsessions and compulsions present in their samples. In consequence, the risk is important to falsely conclude to an absence of impairment. Indeed, the rare studies taking this clinical factor into account pointed out that the cognitive functions are likely to be differently affected across OCD subtypes [29,36,61,78,113-115].

There is another factor which could hamper the reliable identification of cognitive impairments in OCD: the presence of confounding moderators; more precisely, the presence of psychiatric comorbidities and the use of psychotropic drugs. Indeed, it is obvious that OCD is not the only condition affecting cognitive functioning, and the presence of a psychiatric comorbidity, the main one being mood disorders, can lead to misleading conclusions. A similar statement could apply to psychotropic drugs which may affect cognitive functioning. The three meta-analyses by Shin et al. [46••], Abramovitch et al. [47••] and Snyder et al. [48••] addressed this issue and found that neither psychiatric comorbidities, nor psychotropic drugs use influence the cognitive performances.

$<$ Table $1>$

We want to know not only whether an impairment exists, but also how important it is.

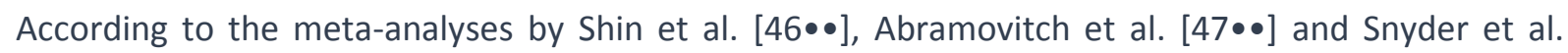
[48••], OCD patients appear to have broad, albeit not severe, cognitive dysfunction (average mean effect size ranging from -0.478 [46••] to -0.499 [47••]; see Table 1$)$. When considering the effect size for each cognitive domain it appears that nearly all of them are mildly impaired with effect sizes ranging from -0.3 to -0.5 approximately, except for planning and for nonverbal memory which present a large effect size (-0.8 approximately) but with a discrepancy between the three metaanalyses. Indeed, Shin et al. [46••] did find a large effect size (-0.732) while Abramovitch et al. [47••] and Snyder et al. [48••] found a medium effect size (-0.44). Concerning the nature of the large effect size found for non-verbal memory, as discussed, it may be related to an alteration in encoding underpinned by a failure in organizational strategies and less with memory impairments per se.

One important criticism that can be made about the neuropsychological tasks used to probe cognitive dysfunctions in $O C D$ is that they lack ecological validity, impairing generalization of the findings. Indeed, for almost all the studies reviewed, subjects perform tasks in a standardized, neutral context. But considering the clinical expression of $O C D$, it is likely that the cognitive 
impairments may be most significant in an OCD-related context. A few studies addressed this issue and effectively found that OCD patients, while presenting no or mild cognitive defects in neutral condition, are significantly impaired in emotional, OCD-related context $[76 \bullet, 81,84,93 \bullet, 107]$. Thus, a way to improve the ecological validity of neuropsychological assessment of OCD patients may rely on the use of virtual reality. As Wiederhold et al. [52•] demonstrated it, virtual reality is a reliable tool to assess cognitive functioning in $O C D$, allowing the implementation of daily living scenarios with emotional context modulation, and therefore improving the ecological validity of the assessment.

Finally, an important question was poorly studied across the literature: are the cognitive dysfunctions in OCD related to symptom severity (i.e. state dependent) or inherent trait properties of OCD? This question has important implications for the use of neuropsychological functioning as an OCD endophenotype. However, the few studies addressing this issue yielded inconsistent results [116•], with some finding a state dependency $[30,117,118]$, while others did not $[19,34,39,56]$.

To conclude, it is important that future research improves the methodological quality of cognitive probing in OCD by taking in account the addressed issues. This improvement may rely on a computational approach, bringing the possibility to use more sensitive and specific measures of cognitive functions. But more generally, it's time to open up to other research fields and to have a more integrative approach, gathering contributions of experimental psychology, neuroimaging, genetics and animal models. Some studies with this approach begin to appear and bring very interesting insights. For example, Palminteri et al. [119], combining a computational approach with neurotransmitter modulation, demonstrated that the serotoninergic system is involved in the procedural learning deficit in OCD. We can also mention Chamberlain et al. [120] who, combining fMRI with cognitive assessment, found that $O C D$ is associated with a reduced activation of orbitofrontal cortex in a reversal learning paradigm. Very interesting too is the study by Da Rocha et al. [121] which, combining genetics with cognitive assessment, found that the BDNF Val66Met polymorphism is associated with impaired decision-making under uncertainty in OCD. These examples demonstrate how this integrative approach is a major way to bring new insights on cognitive functioning in OCD and thus to unveil the neurobiological basis of this disorder [122], potentially leading to the development of more efficient treatments. 


\section{References}

Papers of particular interest, published recently, have been highlighted as:

\section{- Of importance \\ -. Of major importance}

1. Van Ameringen M, Patterson B, Simpson W. Dsm-5 Obsessive-Compulsive and Related Disorders: Clinical Implications of New Criteria. Depress. Anxiety. 2014;31:487-93.

2. Menzies L, Chamberlain SR, Laird AR, Thelen SM, Sahakian BJ, Bullmore ET. Integrating evidence from neuroimaging and neuropsychological studies of obsessive-compulsive disorder: The orbitofronto-striatal model revisited. Neurosci. Biobehav. Rev. 2008;32:525-49.

3. Rotge J-Y, Guehl D, Dilharreguy B, Cuny E, Tignol J, Bioulac B, et al. Provocation of obsessivecompulsive symptoms: a quantitative voxel-based meta-analysis of functional neuroimaging studies. J. Psychiatry Neurosci. JPN. 2008;33:405.

4. Le Jeune F, Vérin M, N'Diaye K, Drapier D, Leray E, Du Montcel ST, et al. Decrease of Prefrontal Metabolism After Subthalamic Stimulation in Obsessive-Compulsive Disorder: A Positron Emission Tomography Study. Biol. Psychiatry. 2010;68:1016-22.

5. Thorsen AL, van den Heuvel OA, Hansen B, Kvale G. Neuroimaging of psychotherapy for obsessivecompulsive disorder: A systematic review. Psychiatry Res. Neuroimaging. 2015;233:306-13.

6. Saxena S, Brody AL, Maidment KM, Dunkin JJ, Colgan M, Alborzian S, et al. Localized Orbitofrontal and Subcortical Metabolic Changes and Predictors of Response to Paroxetine Treatment in Obsessive-Compulsive Disorder. Neuropsychopharmacology. 1999;21:683-93.

7. Squire LR, Dede AJO. Conscious and Unconscious Memory Systems. Cold Spring Harb. Perspect. Biol. 2015;7:a021667.

8. De Geus F Damiaan aJP sitskoorn Margriet M westenberg Herman GM. Attention and cognition in patients with obsessive-compulsive disorder. Psychiatry Clin. Neurosci. 2007;61:45-53.

9. Deckersbach T, Savage CR, Reilly-Harrington N, Clark L, Sachs G, Rauch SL. Episodic memory impairment in bipolar disorder and obsessive-compulsive disorder: the role of memory strategies. Bipolar Disord. 2004;6:233-44.

10. Segalàs $C$, Alonso $P$, Labad J, Jaurrieta N, Real E, Jiménez $S$, et al. Verbal and nonverbal memory processing in patients with obsessive-compulsive disorder: Its relationship to clinical variables. Neuropsychology. 2008;22:262-72.

11. Tükel R, Gürvit H, Ertekin BA, Oflaz S, Ertekin E, Baran B, et al. Neuropsychological function in obsessive-compulsive disorder. Compr. Psychiatry. 2012;53:167-75.

12. Exner C, Kohl A, Zaudig M, Langs G, Lincoln TM, Rief W. Metacognition and episodic memory in obsessive-compulsive disorder. J. Anxiety Disord. 2009;23:624-31.

13. Li B, Sun J-H, Li T, Yang Y-C. Neuropsychological study of patients with obsessive-compulsive disorder and their parents in China: searching for potential endophenotypes. Neurosci. Bull. 2012;28:475-82. 
14. Martin V, Huber M, Rief W, Exner C. Comparative cognitive profiles of obsessive-compulsive disorder and schizophrenia. Arch. Clin. Neuropsychol. 2008;23:487-500.

15. Kashyap H, Kumar JK, Kandavel T, Reddy YCJ. Neuropsychological functioning in obsessivecompulsive disorder: Are executive functions the key deficit? Compr. Psychiatry. 2013;54:533-40.

16. Rajender G, Bhatia MS, Kanwal K, Malhotra S, Singh TB, Chaudhary D. Study of neurocognitive endophenotypes in drug-naïve obsessive-compulsive disorder patients, their first-degree relatives and healthy controls: Neurocognitive endophenotypes in OCD. Acta Psychiatr. Scand. 2011;124:15261.

17. Spalletta G, Piras F, Fagioli S, Caltagirone C, Piras F. Brain microstructural changes and cognitive correlates in patients with pure obsessive compulsive disorder. Brain Behav. 2014;4:261-77.

18. Lennertz L, Rampacher F, Vogeley A, Schulze-Rauschenbach S, Pukrop R, Ruhrmann S, et al. Antisaccade performance in patients with obsessive-compulsive disorder and unaffected relatives: further evidence for impaired response inhibition as a candidate endophenotype. Eur. Arch. Psychiatry Clin. Neurosci. 2012;262:625-34.

19. Rao NP, Reddy YCJ, Kumar KJ, Kandavel T, Chandrashekar CR. Are neuropsychological deficits trait markers in OCD? Prog. Neuropsychopharmacol. Biol. Psychiatry. 2008;32:1574-9.

20. Schmidtke K, Schorb A, Winkelmann G, Hohagen F. Cognitive Frontal Lobe Dysfunction in Obsessive-Compulsive Disorder. Biol. Psychiatry. 1998;43:666-73.

21. Boldrini M, Del Pace L, Placidi GPA, Keilp J, Ellis SP, Signori S, et al. Selective cognitive deficits in obsessive-compulsive disorder compared to panic disorder with agoraphobia. Acta Psychiatr. Scand. 2005;111:150-8.

22. Demeter G, Racsmány M, Csigó K, Harsányi A, Németh A, Döme L. Intact short-term memory and impaired executive functions in obsessive compulsive disorder. Ideggyógy. Szle. 2013;66:35-41.

23. Morein-Zamir S, Craig KJ, Ersche KD, Abbott S, Muller U, Fineberg NA, et al. Impaired visuospatial associative memory and attention in obsessive compulsive disorder but no evidence for differential dopaminergic modulation. Psychopharmacology (Berl.). 2010;212:357-67.

24. Moritz S, Birkner C, Kloss M, Jahn H, Hand I, Haasen C, et al. Executive functioning in obsessivecompulsive disorder, unipolar depression, and schizophrenia. Arch. Clin. Neuropsychol. 2002;17:47783.

25. Kim M-S, Kang S-S, Youn T, Kang D-H, Kim J-J, Kwon JS. Neuropsychological correlates of P300 abnormalities in patients with schizophrenia and obsessive-compulsive disorder. Psychiatry Res. Neuroimaging. 2003;123:109-23.

26. Chamberlain SR, Blackwell AD, Fineberg NA, Robbins TW, Sahakian BJ. The neuropsychology of obsessive compulsive disorder: the importance of failures in cognitive and behavioural inhibition as candidate endophenotypic markers. Neurosci. Biobehav. Rev. 2005;29:399-419.

27. Deckersbach T, Savage CR, Dougherty DD, Bohne A, Loh R, Nierenberg A, et al. Spontaneous and directed application of verbal learning strategies in bipolar disorder and obsessive-compulsive disorder. Bipolar Disord. 2005;7:166-75.

28. Olley A, Malhi G, Sachdev P. Memory and executive functioning in obsessive-compulsive disorder: A selective review. J. Affect. Disord. 2007;104:15-23.

29. Jang JH, Kim HS, Ha TH, Shin NY, Kang D-H, Choi J-S, et al. Nonverbal memory and organizational dysfunctions are related with distinct symptom dimensions in obsessive-compulsive disorder. Psychiatry Res. 2010;180:93-8. 
30. Katrin Kuelz A, Riemann D, Halsband U, Vielhaber K, Unterrainer J, Kordon A, et al. Neuropsychological Impairment in Obsessive-Compulsive Disorder-Improvement Over the Course of Cognitive Behavioral Treatment. J. Clin. Exp. Neuropsychol. 2006;28:1273-87.

31. Kwon JS, Kim J-J, Lee DW, Lee JS, Lee DS, Kim M-S, et al. Neural correlates of clinical symptoms and cognitive dysfunctions in obsessive-compulsive disorder. Psychiatry Res. Neuroimaging. 2003;122:37-47.

32. Mataix-Cols D, Alonso P, Hernández R, Deckersbach T, Savage CR, Menchón JM, et al. Relation of neurological soft signs to nonverbal memory performance in obsessive-compulsive disorder. J. Clin. Exp. Neuropsychol. 2003;25:842-851.

33. Penadés $R$, Catalán $R$, Andrés $S$, Salamero $M$, Gastó $C$. Executive function and nonverbal memory in obsessive-compulsive disorder. Psychiatry Res. 2005;133:81-90.

34. Roh KS, Shin MS, Kim M-S, Ha T-H, Shin Y-W, Lee KJ, et al. Persistent cognitive dysfunction in patients with obsessive-compulsive disorder: A naturalistic study. Psychiatry Clin. Neurosci. 2005;59:539-545.

35. Lacerda ALT, Dalgalarrondo P, Caetano D, Haas GL, Camargo EE, Keshavan MS. Neuropsychological performance and regional cerebral blood flow in obsessive-compulsive disorder. Prog. Neuropsychopharmacol. Biol. Psychiatry. 2003;27:657-65.

36. Nedeljkovic M [b1] (analytic), Kyrios M [b1] (analytic), Moulding R [b2] (analytic), Doron G [b3] (analytic), Wainwright K [b4] (analytic), Pantelis C [b5] (analytic), et al. Differences in neuropsychological performance between subtypes of obsessive-compulsive disorder (English). Aust NZ J Psychiatr. 2009;43:216-26.

37. Watkins LH, Sahakian BJ, Robertson MM, Veale DM, Rogers RD, Pickard KM, et al. Executive function in Tourette's syndrome and obsessive-compulsive disorder. Psychol. Med. 2005;35:571-82.

38. Chamberlain SR, Fineberg NA, Blackwell AD, Clark L, Robbins TW, Sahakian BJ. A neuropsychological comparison of obsessive-compulsive disorder and trichotillomania. Neuropsychologia. 2007;45:654-62.

39. Nielen MMA, Den Boer JA. Neuropsychological performance of OCD patients before and after treatment with fluoxetine: evidence for persistent cognitive deficits. Psychol. Med. 2003;33:917-25.

40. Purcell R, Maruff P, Kyrios M, Pantelis C. Cognitive Deficits in Obsessive-Compulsive Disorder on Tests of Frontal-Striatal Function. Biol. Psychiatry. 1998;43:348-57.

41. Purcell R, Maruff $P$, Kyrios $M$, Pantelis $C$. Neuropsychological deficits in obsessive-compulsive disorder: A comparison with unipolar depression, panic disorder, and normal controls. Arch. Gen. Psychiatry. 1998;55:415-23.

42. Bersani G, Quartini A, Ratti F, Pagliuca G, Gallo A. Olfactory identification deficits and associated response inhibition in obsessive-compulsive disorder: On the scent of the orbitofronto-striatal model. Psychiatry Res. 2013;210:208-14.

43. de Vries FE, de Wit SJ, Cath DC, van der Werf YD, van der Borden V, van Rossum TB, et al. Compensatory Frontoparietal Activity During Working Memory: An Endophenotype of ObsessiveCompulsive Disorder. Biol. Psychiatry. 2014;76:878-87.

44. Trivedi JK, Dhyani M, Goel D, Sharma S, Singh AP, Sinha PK, et al. Neurocognitive dysfunction in patients with obsessive compulsive disorder. Afr. J. Psychiatry. 2008;11:204-209.

45. Aigner M, Sachs G, Bruckmüller E, Winklbaur B, Zitterl W, Kryspin-Exner I, et al. Cognitive and emotion recognition deficits in obsessive-compulsive disorder. Psychiatry Res. 2007;149:121-8. 
46.• Shin NY, Lee TY, Kim E, Kwon JS. Cognitive functioning in obsessive-compulsive disorder: a meta-analysis. Psychol. Med. 2013;44:1121-30. One of the only three meta-analyses assessing cognitive functioning in OCD and including a total of 3070 patients through 88 studies.

47.• Abramovitch A, Abramowitz JS, Mittelman A. The neuropsychology of adult obsessivecompulsive disorder: A meta-analysis. Clin. Psychol. Rev. 2013;33:1163-71. One of the only three meta-analyses assessing cognitive functioning in OCD and including a total of 3452 patients through 113 studies.

48.• Snyder HR, Kaiser RH, Warren SL, Heller W. Obsessive-Compulsive Disorder Is Associated With Broad Impairments in Executive Function A Meta-Analysis. Clin. Psychol. Sci. $2014 ; 2167702614534210$. One of the only three meta-analyses assessing cognitive functioning in OCD and including a total of 3162 patients through 110 studies.

49. Gambini O, Abbruzzese M, Scarone S. Smooth pursuit and saccadic eye movements and Wisconsin card sorting test performance in obsessive- compulsive disorder. Psychiatry Res. 1993;48:191-200.

50. Kıvırcık BB, Yener GG, Alptekin K, Aydın H. Event-related potentials and neuropsychological tests in obsessive-compulsive disorder. Prog. Neuropsychopharmacol. Biol. Psychiatry. 2003;27:601-6.

51. Zhang J, Yang X, Yang Q, Zhang J, Yang X, Yang Q. Neuropsychological dysfunction in adults with early-onset obsessive-compulsive disorder: the search for a cognitive endophenotype. Rev. Bras. Psiquiatr. 2015;00-00.

52. Wiederhold BK, Riva G. Cognitive Assessment of OCD Patients: NeuroVR vs Neuropsychological Test. Annu. Rev. Cybertherapy Telemed. 2014 Posit. Change Connect. Virtual Real. 2014;199:40. A study demonstrating the reliability and the far better ecological validity of a virtual reality paradigm to assess cognitive functioning in OCD.

53. Armstrong T, Zald DH, Olatunji BO. Attentional control in OCD and GAD: Specificity and associations with core cognitive symptoms. Behav. Res. Ther. 2011;49:756-62.

54. Koch J, Exner C. Selective attention deficits in obsessive-compulsive disorder: The role of metacognitive processes. Psychiatry Res. 2015;225:550-5.

55. Johannes S, Wieringa BM, Nager W, Rada D, Dengler R, Emrich HM, et al. Discrepant target detection and action monitoring in obsessive-compulsive disorder. Psychiatry Res. Neuroimaging. 2001;108:101-10.

56. Bannon S, Gonsalvez CJ, Croft RJ, Boyce PM. Executive functions in obsessive-compulsive disorder: state or trait deficits? Aust. N. Z. J. Psychiatry. 2006;40:1031-1038.

57. Bradbury C, Cassin SE, Rector NA. Obsessive beliefs and neurocognitive flexibility in obsessivecompulsive disorder. Psychiatry Res. 2011;187:160-5.

58. Cavedini P, Zorzi C, Piccinni M, Cavallini MC, Bellodi L. Executive Dysfunctions in ObsessiveCompulsive Patients and Unaffected Relatives: Searching for a New Intermediate Phenotype. Biol. Psychiatry. 2010;67:1178-84.

59.• Kim HW, Kang Jl, Namkoong K, Jhung K, Ha RY, Kim SJ. Further evidence of a dissociation between decision-making under ambiguity and decision-making under risk in obsessive-compulsive disorder. J. Affect. Disord. 2015;176:118-24. A study which has pointed an altered decision making only in an ambiguous/uncertain context, underlining the need to take in account this factor for future research. 
60. Lucey JV, Burness CE, Costa DC, Gacinovic S, Pilowsky LS, Ell PJ, et al. Wisconsin Card Sorting Task (WCST) errors and cerebral blood flow in obsessive-compulsive disorder (OCD). Br. J. Med. Psychol. 1997;70:403-11.

61. Okasha A, Rafaat M, Mahallawy N, Nahas GE, Dawla ASE, Sayed M, et al. Cognitive dysfunction in obsessive-compulsive disorder. Acta Psychiatr. Scand. 2000;101:281-5.

62. Fenger MM, Gade A, Adams KH, Hansen ES, Bolwig TG, Knudsen GM. Cognitive deficits in obsessive-compulsive disorder on tests of frontal lobe functions. Nord. J. Psychiatry. 2005;59:39-44.

63. Kohli A, Rana DK, Gupta N, Kulhara P. Neuropsychological Assessment in Obsessive-Compulsive Disorder. Indian J. Psychol. Med. 2015;37:205-11.

64. Endrass T, Koehne S, Riesel A, Kathmann N. Neural correlates of feedback processing in obsessive-compulsive disorder. J. Abnorm. Psychol. 2013;122:387-96.

65. Remijnse PL, Nielen MA, van Balkom AM, et al. REduced orbitofrontal-striatal activity on a reversal learning task in obsessive-compulsive disorder. Arch. Gen. Psychiatry. 2006;63:1225-36.

66. Remijnse PL, Nielen MMA, van Balkom AJLM, Hendriks G-J, Hoogendijk WJ, Uylings HBM, et al. Differential frontal-striatal and paralimbic activity during reversal learning in major depressive disorder and obsessive-compulsive disorder. Psychol. Med. 2009;39:1503.

67. Szabó C, Németh A, Kéri S. Ethical sensitivity in obsessive-compulsive disorder and generalized anxiety disorder: The role of reversal learning. J. Behav. Ther. Exp. Psychiatry. 2013;44:404-10.

68. Valerius G, Lumpp A, Kuelz A-K, Freyer T, Voderholzer U. Reversal learning as a neuropsychological indicator for the neuropathology of obsessive compulsive disorder? A behavioral study. J. Neuropsychiatry Clin. Neurosci. 2008;20:210-218.

69. Morein-Zamir S, Papmeyer M, Pertusa A, Chamberlain SR, Fineberg NA, Sahakian BJ, et al. The profile of executive function in OCD hoarders and hoarding disorder. Psychiatry Res. [Internet]. 2013 [cited 2014 Jan 31]; Available from: http://www.sciencedirect.com/science/article/pii/S0165178113008196

70. Chamberlain MA Samuel, Fineberg MD Naomi, Blackwell PD Andrew, Robbins PD Trevor, Sahakian PD Barbara. Motor Inhibition and Cognitive Flexibility in Obsessive-Compulsive Disorder and Trichotillomania. Am. J. Psychiatry. 2006;163:1282-4.

71. Chamberlain MA Samuel, Fineberg MBBS Naomi, Menzies BA Lara, Blackwell PD Andrew, Bullmore MB /B. C Edward, Robbins PD Trevor, et al. Impaired Cognitive Flexibility and Motor Inhibition in Unaffected First-Degree Relatives of Patients With Obsessive-Compulsive Disorder. Am. J. Psychiatry. 2007;164:335-8.

72. Veale DM, Sahakian BJ, Owen AM, Marks IM. Specific cognitive deficits in tests sensitive to frontal lobe dysfunction in obsessive-compulsive disorder. Psychol. Med. 1996;26:1261-9.

73. Gu B-M, Park J-Y, Kang D-H, Lee SJ, Yoo SY, Jo HJ, et al. Neural correlates of cognitive inflexibility during task-switching in obsessive-compulsive disorder. Brain. 2008;131:155-64.

74. Moritz S, Hübner M, Kluwe R. Task switching and backward inhibition in obsessive-compulsive disorder. J. Clin. Exp. Neuropsychol. 2004;26:677-683.

75. Remijnse PL, van den Heuvel OA, Nielen MMA, Vriend C, Hendriks G-J, Hoogendijk WJG, et al. Cognitive Inflexibility in Obsessive-Compulsive Disorder and Major Depression Is Associated with Distinct Neural Correlates. PLoS ONE. 2013;8:e59600. 
76. Zetsche U, Rief W, Westermann S, Exner C. Cognitive deficits are a matter of emotional context: Inflexible strategy use mediates context-specific learning impairments in OCD. Cogn. Emot. 2015;29:360-71. A study which has demonstrated the importance to consider the emotional context when assessing cognitive functioning, and in this case behavioral flexibility.

77. van Velzen LS, Vriend C, de Wit SJ, van den Heuvel OA. Response inhibition and interference control in obsessive-compulsive spectrum disorders. Front. Hum. Neurosci. 2014;8:419.

78. Dittrich WH, Johansen T. Cognitive deficits of executive functions and decision-making in obsessive-compulsive disorder. Scand. J. Psychol. 2013;54:393-400.

79. Gehring WJ, Himle J, Nisenson LG. Action-Monitoring Dysfunction in Obsessive-Compulsive Disorder. Psychol. Sci. 2000;11:1-6.

80. Bannon S, Gonsalvez CJ, Croft RJ, Boyce PM. Response inhibition deficits in obsessive-compulsive disorder. Psychiatry Res. 2002;110:165-74.

81. Cohen $\mathrm{Y}$, Lachenmeyer JR, Springer C. Anxiety and selective attention in obsessive-compulsive disorder. Behav. Res. Ther. 2003;41:1311-23.

82. Penadés R, Catalán R, Rubia $K$, Andrés $S$, Salamero $M$, Gastó $C$. Impaired response inhibition in obsessive compulsive disorder. Eur. Psychiatry. 2007;22:404-10.

83. Moritz S, Kloss M, Jelinek L. Negative priming (cognitive inhibition) in obsessive-compulsive disorder (OCD). J. Behav. Ther. Exp. Psychiatry. 2010;41:1-5.

84. Bohne A, Keuthen NJ, Tuschen-Caffier B, Wilhelm S. Cognitive inhibition in trichotillomania and obsessive-compulsive disorder. Behav. Res. Ther. 2005;43:923-42.

85. Endrass T, Riesel A, Kathmann N, Buhlmann U. Performance monitoring in obsessive-compulsive disorder and social anxiety disorder. J. Abnorm. Psychol. 2014;123:705-14.

86. Riesel A, Kathmann N, Endrass T. Overactive performance monitoring in obsessive-compulsive disorder is independent of symptom expression. Eur. Arch. Psychiatry Clin. Neurosci. 2014;264:70717.

87. Klawohn J, Riesel A, Grützmann R, Kathmann N, Endrass T. Performance monitoring in obsessivecompulsive disorder: A temporo-spatial principal component analysis. Cogn. Affect. Behav. Neurosci. 2014;14:983-95.

88. Riesel A, Endrass T, Auerbach LA, Kathmann N. Overactive Performance Monitoring as an Endophenotype for Obsessive-Compulsive Disorder: Evidence From a Treatment Study. Am. J. Psychiatry. 2015;172:665-73.

89. Riesel A, Endrass T, Kaufmann C, Kathmann N. Overactive Error-Related Brain Activity as a Candidate Endophenotype for Obsessive-Compulsive Disorder: Evidence From Unaffected FirstDegree Relatives. Am. J. Psychiatry. 2011;168:317-24.

90. Endrass T, Schuermann B, Kaufmann C, Spielberg R, Kniesche R, Kathmann N. Performance monitoring and error significance in patients with obsessive-compulsive disorder. Biol. Psychol. 2010;84:257-63.

91. Endrass T, Klawohn J, Schuster F, Kathmann N. Overactive performance monitoring in obsessivecompulsive disorder: ERP evidence from correct and erroneous reactions. Neuropsychologia. 2008;46:1877-87.

92. Morein-Zamir S, Fineberg NA, Robbins TW, Sahakian BJ. Inhibition of thoughts and actions in obsessive-compulsive disorder: extending the endophenotype? Psychol. Med. 2010;40:263-72. 
93. Morein-Zamir S, Papmeyer M, Gillan CM, Crockett MJ, Fineberg NA, Sahakian BJ, et al. Punishment promotes response control deficits in obsessive-compulsive disorder: evidence from a motivational go/no-go task. Psychol. Med. 2013;43:391-400. A study which has demonstrated the importance to consider the emotional context when assessing cognitive functioning, and in this case inhibitory control.

94. Bohne A, Savage CR, Deckersbach T, Keuthen NJ, Wilhelm S. Motor inhibition in trichotillomania and obsessive-compulsive disorder. J. Psychiatr. Res. 2008;42:141-50.

95. Herrmann MJ, Jacob C, Unterecker S, Fallgatter AJ. Reduced response-inhibition in obsessivecompulsive disorder measured with topographic evoked potential mapping. Psychiatry Res. 2003;120:265-71.

96. Kim M-S, Kim YY, Yoo SY, Kwon JS. Electrophysiological correlates of behavioral response inhibition in patients with obsessive-compulsive disorder. Depress. Anxiety. 2007;24:22-31.

97. Maltby N, Tolin DF, Worhunsky P, O'Keefe TM, Kiehl KA. Dysfunctional action monitoring hyperactivates frontal-striatal circuits in obsessive-compulsive disorder: an event-related fMRI study. Neurolmage. 2005;24:495-503.

98. Roth RM, Saykin AJ, Flashman LA, Pixley HS, West JD, Mamourian AC. Event-Related Functional Magnetic Resonance Imaging of Response Inhibition in Obsessive-Compulsive Disorder. Biol. Psychiatry. 2007;62:901-9.

99. Ruchsow M, Reuter K, Hermle L, Ebert D, Kiefer M, Falkenstein M. Executive control in obsessivecompulsive disorder: event-related potentials in a Go/Nogo task. J. Neural Transm. 2007;114:1595601.

100. Tolin DF, Witt ST, Stevens MC. Hoarding disorder and obsessive-compulsive disorder show different patterns of neural activity during response inhibition. Psychiatry Res. Neuroimaging. 2014;221:142-8.

101. Thomas SJ, Gonsalvez CJ, Johnstone SJ. How specific are inhibitory deficits to obsessivecompulsive disorder? A neurophysiological comparison with panic disorder. Clin. Neurophysiol. [Internet]. $2013 \quad$ [cited $2014 \quad$ Feb 18]; Available from: http://www.sciencedirect.com/science/article/pii/S1388245713010080

102. Boisseau CL, Thompson-Brenner H, Caldwell-Harris C, Pratt E, Farchione T, Harrison Barlow D. Behavioral and cognitive impulsivity in obsessive-compulsive disorder and eating disorders. Psychiatry Res. 2012;200:1062-6.

103. de Wit SJ, de Vries FE, van der Werf YD, Cath DC, Heslenfeld DJ, Veltman EM, et al. Presupplementary Motor Area Hyperactivity During Response Inhibition: A Candidate Endophenotype of Obsessive-Compulsive Disorder. Am. J. Psychiatry. 2012;169:1100-8.

104. Kang D-H, Jang JH, Han JY, Kim J-H, Jung WH, Choi J-S, et al. Neural correlates of altered response inhibition and dysfunctional connectivity at rest in obsessive-compulsive disorder. Prog. Neuropsychopharmacol. Biol. Psychiatry. 2013;40:340-6.

105. Menzies L, Achard S, Chamberlain SR, Fineberg N, Chen C-H, Campo N del, et al. Neurocognitive endophenotypes of obsessive-compulsive disorder. Brain. 2007;130:3223-36.

106. Sohn SY, Kang JI, Namkoong K, Kim SJ. Multidimensional Measures of Impulsivity in ObsessiveCompulsive Disorder: Cannot Wait and Stop. PLoS ONE. 2014;9:e111739.

107. Bannon S, Gonsalvez CJ, Croft RJ. Processing impairments in OCD: It is more than inhibition! Behav. Res. Ther. 2008;46:689-700. 
108. Shao Z, Janse E, Visser K, Meyer AS. What do verbal fluency tasks measure? Predictors of verbal fluency performance in older adults. Lang. Sci. 2014;5:772.

109. van den Heuvel OA, Veltman DJ, Groenewegen HJ, et al. FRontal-striatal dysfunction during planning in obsessive-compulsive disorder. Arch. Gen. Psychiatry. 2005;62:301-9.

110. Nielen MMA, Veltman DJ, de Jong R, Mulder G, den Boer JA. Decision making performance in obsessive compulsive disorder. J. Affect. Disord. 2002;69:257-60.

111. Banca P, Vestergaard MD, Rankov V, Baek K, Mitchell S, Lapa T, et al. Evidence Accumulation in Obsessive-Compulsive Disorder: the Role of Uncertainty and Monetary Reward on Perceptual Decision-Making Thresholds. Neuropsychopharmacology [Internet]. 2014 [cited 2015 Mar 27]; Available from: http://www.nature.com/npp/journal/vaop/ncurrent/full/npp2014303a.html A study which has pointed an altered decision making only under high level of uncertainty, underlining the need to consider this factor in future research.

112. Abramowitz JS, Deacon BJ, Olatunji BO, Wheaton MG, Berman NC, Losardo D, et al. Assessment of obsessive-compulsive symptom dimensions: Development and evaluation of the Dimensional Obsessive-Compulsive Scale. Psychol. Assess. 2010;22:180-98.

113. Cha KR, Koo M-S, Kim C-H, Kim JW, Oh W-J, Suh HS, et al. Nonverbal memory dysfunction in obsessive-compulsive disorder patients with checking compulsions. Depress. Anxiety. 2008;25:E11520.

114. Hashimoto N, Nakaaki S, Omori IM, Fujioi J, Noguchi $\mathrm{Y}$, Murata $\mathrm{Y}$, et al. Distinct neuropsychological profiles of three major symptom dimensions in obsessive-compulsive disorder. Psychiatry Res. 2011;187:166-73.

115. Omori IM, Murata Y, Yamanishi T, Nakaaki S, Akechi T, Mikuni M, et al. The differential impact of executive attention dysfunction on episodic memory in obsessive-compulsive disorder patients with checking symptoms vs. those with washing symptoms. J. Psychiatr. Res. 2007;41:776-84.

116. Vandborg SK, Hartmann TB, Bennedsen BE, Pedersen AD, Eskildsen A, Videbech PBH, et al. Do cognitive functions in obsessive-compulsive disorder change after treatment? A systematic review and a double case report. Nord. J. Psychiatry. 2012;66:60-7. A systematic review exploring the question of strait/trait-dependency of cognitive impairments in $O C D$, underlining the inconsistency of actual results and the need for more investigations.

117. Vriend C, de Wit SJ, Remijnse PL, van Balkom AJLM, Veltman DJ, van den Heuvel OA. Switch the itch: A naturalistic follow-up study on the neural correlates of cognitive flexibility in obsessivecompulsive disorder. Psychiatry Res. Neuroimaging. 2013;213:31-8.

118. Nakao T, Nakagawa A, Yoshiura T, Nakatani E, Nabeyama M, Yoshizato C, et al. Brain activation of patients with obsessive-compulsive disorder during neuropsychological and symptom provocation tasks before and after symptom improvement: A functional magnetic resonance imaging study. Biol. Psychiatry. 2005;57:901-10.

119. Palminteri S, Clair A-H, Mallet L, Pessiglione M. Similar Improvement of Reward and Punishment Learning by Serotonin Reuptake Inhibitors in Obsessive-Compulsive Disorder. Biol. Psychiatry. 2012;72:244-50.

120. Chamberlain SR, Menzies L, Hampshire A, Suckling J, Fineberg NA, del Campo N, et al. Orbitofrontal Dysfunction in Patients with Obsessive-Compulsive Disorder and Their Unaffected Relatives. Science. 2008;321:421-2. 
121. da Rocha FF, Malloy-Diniz L, Lage NV, Corrêa H. The relationship between the Met allele of the BDNF Val66Met polymorphism and impairments in decision making under ambiguity in patients with obsessive-compulsive disorder. Genes Brain Behav. 2011;10:523-9.

122. Burguière $E$, Monteiro $P$, Mallet L, Feng G, Graybiel AM. Striatal circuits, habits, and implications for obsessive-compulsive disorder. Curr. Opin. Neurobiol. 2015;30:59-65.

Table 1. Summary of cognitive impairments in OCD according to three meta-analyses.

\begin{tabular}{|c|c|c|c|c|}
\hline & Trend & & Effect size & \\
\hline & & Shin et al. $[46 \bullet \bullet]$ & Abramovitch et al. [47••] & Snyder et al. $[48 \bullet \bullet]$ \\
\hline Verbal memory & $\searrow$ & -0.441 & -0.332 & -0.31 \\
\hline Nonverbal memory & $\searrow$ & -0.624 & -0.761 & -0.47 \\
\hline Focused attention & $\searrow$ & -0.444 & NA & -0.57 \\
\hline Sustained attention & $\searrow$ & -0.452 & -0.499 & NA \\
\hline Selective attention & $\searrow$ & NA & NA & NA \\
\hline Divided attention & $\searrow$ & NA & NA & NA \\
\hline Flexibility & $\searrow$ & -0.373 to -0.511 & -0.517 & -0.5 \\
\hline Cognitive inhibition & $\searrow$ & -0.547 & -0.54 & \\
\hline Behavioral inhibition & $\searrow$ & NA & -0.33 & -0.37 \\
\hline Verbal fluency & $\searrow$ & -0.385 to -0.415 & NA & -0.36 \\
\hline Planning & $\searrow$ & -0.732 & -0.44 & -0.44 \\
\hline Decision-making & $\searrow$ & NA & NA & NA \\
\hline
\end{tabular}

A negative effect size reflects an impairment.

Interpretation: $<0.2=$ unsignificant; $0.2-0.5=$ small; $0.5-0.8=$ moderate $;>0.8=$ large

NA: Not Assessed 